•生物编目・

\title{
广东车八岭国家级自然保护区大型底栖动物多样性
}

\author{
易祖盛 ${ }^{*}$, 黄元骏 ${ }^{\mathbb{1}} 1$, 易晖 ${ }^{2}$, 张新旺 ${ }^{3}$, 李文俊 ${ }^{1}$
}

1. 广州大学生命科学学院, 广州 510006; 2. 广州工程技术职业学院, 广州 510075; 3. 广东车八岭国家级自然保护区管理局, 广东韶关 512500

摘要: 大型底栖动物在当地生物多样性、食物链构成、水质指示和物质循环中有重要的作用, 但目前国内对森林内陆水体(湖 泊、水库、溪流)中的大型底栖动物综合调查较少。作者于2019、2020年对广东车八岭国家级自然保护区的9个采样点开展了 大型底栖动物的定性调查, 采样点涵盖保护区不同功能区、海拔、水体环境和水体底质。共鉴定出大型底栖动物4门6纲18目 38 科57种, 水生昆虫稚虫占大多数, 且多喜好清洁流动水体。在低海拔实验区即可采集到种类与数量可观的清洁水体指示物 种。当地的大型底栖动物以亚热带森林典型物种为主，多偏好栖息于流动水体，反映了保护区的物种区系及其水体环境。本 研究可为保护区的物种编目、环境评估和长期监测提供基础资料。

关键词: 车八岭; 自然保护区; 大型底栖动物; 多样性调查

易祖盛, 黄元骏, 易晖, 张新旺, 李文俊 (2021) 广东车八岭国家级自然保护区大型底栖动物多样性. 生物多样性, 29, 680-687. doi: 10.17520/biods.2020304.

Yi ZS, Huang YJ, Yi H, Zhang XW, Li WJ (2021) Biodiversity of macrozoobenthos in the Chebaling National Nature Reserve, Guangdong Province. Biodiversity Science, 29, 680-687. doi: 10.17520/biods.2020304.

\section{Biodiversity of macrozoobenthos in the Chebaling National Nature Reserve, Guangdong Province}

Zusheng $\mathrm{Yi}^{\mathbb{D}_{1^{*}}}$, Yuanjun Huang ${ }^{\mathbb{1}_{1}}$, Hui Yi ${ }^{2}$, Xinwang Zhang ${ }^{3}$, Wenjun $\mathrm{Li}^{1}$

1 School of Life Sciences, Guangzhou University, Guangzhou 510006

2 Guangzhou Institute of Technology, Guangzhou 510075

3 Guangdong Chebaling National Nature Reserve Administration Bureau, Shaoguan, Guangdong 512500

\section{ABSTRACT}

Aim: Zoobenthos are important components of local biodiversity, food webs, and biogeochemical circulation processes, and are important water quality indicators. Despite their recognized importance, current research on freshwater macrozoobenthic fauna in forested inland water bodies (reservoirs, lakes, streams) in China is lacking. To better understand macrozoobenthic communities and their ecosystem services in these habitats, we choose a typical subtropical forest reserve, the Chebaling National Nature Reserve for investigation.

Methods: We conducted a two-year (2019-2020) systematic field survey across nine sampling sites of different substrates in the Chebaling National Nature Reserve, Guangdong Province. These sites encompassed experimental, buffer, and core zones, and elevations stretched from $345 \mathrm{~m}$ to $751 \mathrm{~m}$. The surveyed habitats included forested rivers, mountain streams, ponds, reservoirs, paddy fields, and ditches, which contained substrates comprising rock, gravel, sand, hardened riverbed, and silt. We applied multiple methods to survey the various habitats, including dip netting in shallow water, brushes and tweezers to isolate attached species under rocks, and baits and shrimp cages to capture species in deep water. During field surveys, we measured species composition and their population levels. We then analyzed metrics of species composition, spatial distribution, environmental indicators, and ecosystem function.

Results: In total, we identified 57 species of macrobenthic fauna (belonging to 4 phylum, 6 classes, 18 orders, and 38 families) in the reserve. Eighty percent of species were arthropods, and $90 \%$ of arthropods were aquatic insects and their nymphs. We recorded 22 species and 8 families of nymphs in Odonata (dragonflies and damselflies), which constituted 38\% of all captured species. Nymphs of EPT (Ephemeroptera, Plecoptera, and Trichoptera) species

收稿日期: 2020-07-31; 接受日期: 2021-01-25

基金项目: 《车八岭鱼类及常见底栖动物图谱》编撰项目 (CBLHT-201973)

* 通讯作者 Author for correspondence. E-mail: 13533015500@139.com 
constituted 22\% of all species. We commonly recorded Semisulcospira libertina in various flowing water bodies, along with a considerable population of pristine water indicator species in the low-altitude experimental area.

Conclusion: Macrozoobenthic fauna in Chebaling National Nature Reserve comprised species typical of subtropical forest freshwater ecosystems. Large proportions of species that favored flowing water conditions were recorded in sites with various water bodies and elevations, and were even recorded in disturbed sites (i.e., in both experimental areas and artificial water bodies). Most species were water quality indicators that reflected the major water forms and overall quality of the reserve. The high diversity of aquatic predatory insects we recorded indicates that there is a sufficient amount of small prey in the ecosystem. Furthermore, our results suggest that the diverse and abundant macrozoobenthos can serve as considerable source of prey to predators in the reserve. Overall, our results provide data to inventory zoobenthic species and perform environmental assessments, which can further be enhanced by continued long-term monitoring of zoobenthos in the Chebaling National Nature Reserve.

Key words: Chebaling; nature reserve; macrozoobenthos; biodiversity; community composition; ecosystem services

底栖动物是指生活史中大部分时间在水体底 部活动的无脊椎动物 (生态学名词审定委员会, 2006), 既包含附着于水体底质的定栖物种(如贝类、 浴虫), 也包含在水体底部自由活动的物种(如节肢 动物)。大型底栖动物是指其中能被 $0.5 \mathrm{~mm}$ 网篮截留, 即体长或宽度大于 $0.5 \mathrm{~mm}$ 的种类(李新正, 2011)。大 型底栖动物的门类繁多, 在当地物质循环和能量流 动上发挥着重要作用(杨明生, 2009; 蒋小明等, 2011; 李斌等, 2013; 邢圆等, 2019)。此外, 底栖动 物是捕食性昆虫、鱼类、两栖类及湿地鸟类的重要 食物, 是当地食物链和食物网的基础组成及重要环 节, 对维持当地生物多样性有着重要作用(杨明生, 2009; 李玲, $2018^{(1)}$ )。

目前国内保护区的底栖动物多样性调查大多 集中于滨海红树林、河口、河流等大型水体, 对内 陆水体, 尤其是亚热带森林内陆水体(湖泊水库、溪 流)的底栖动物综合调查较少(汪兴中, 2012)。广东 车八岭国家级自然保护区(以下简称车八岭保护区) 属于亚热带季风气候, 保存有较完整的中亚热带常 绿阔叶林(徐燕千, 1993), 其水体的底栖动物具备一 定多样性和地域特色。早在 20 世纪末, 车八岭保护 区就组织了动植物资源的综合调查, 并在1993年汇 编了保护区调查研究论文集(徐燕千, 1993), 涵盖植 物、真菌、陆生脊椎动物、鱼类、昆虫等诸多门类, 但至今尚未见底栖动物的系统调查。近年来, 车八 岭保护区多次发现新物种记录或新物种, 特别是以 当地地名命名、稚虫营底栖生活的车八岭星齿蛉 (Protohermes chebalingensis) 和车八岭越南蜉 (Vietnamella chebalingensis)的发现(杨定和刘星月,

(1) 李玲 (2018) 冬季长白山源头溪流生境类型对调落叶分解与底栖动 物定殖的影响. 硕士学位论文, 东北师范大学, 长春。
2010; Luo et al, 2020), 表明该地区的底栖动物有待 进一步研究。

受广东车八岭保护区管理局所托, 我们于 2019-2020年对保护区9个不同环境水体中的大型 底栖动物多样性进行了系统调查, 涵盖实验区至核 心区。从物种构成、空间分布、环境指示、生态系 统功能四个方面分析了保护区底栖动物的群落结 构特征及其作用, 以期为保护区乃至类似环境的物 种编目、环境评价、生物多样性保护提供参考。

\section{调查区域及方法}

\section{1 调查区域概况}

车八岭保护区位于始兴县东南部, 东面与江西 全南县相接。其地理坐标为 $24^{\circ} 40^{\prime}-24^{\circ} 46^{\prime} \mathrm{N}$, $114^{\circ} 07^{\prime}-114^{\circ} 16^{\prime} \mathrm{E}$, 面积约 $75.45 \mathrm{~km}^{2}$ 。年均气温 $19.6{ }^{\circ} \mathrm{C}$, 年均降水量 $1,468 \mathrm{~mm}$ 。全年热量充足, 冷 暖交替明显。春季低温阴雨寡照, 夏季炎热高温多 雨, 秋季昼暖夜凉, 冬季有霜稀雨(宋相金等, 2017; 肖治术等, 2019)。

保护区是珠江最大支流暨珠江三角洲的重要 水源地一一北江的上游东北支流发源地。由于保护 区山地切割强烈, 坡陡谷深, 加之区内降水较为丰 富, 形成多处溪流与深潭, 并汇于保护区中部形成 保护区内的主要河流——樟栋水(宋相金等, 2017)。 此外, 在车八岭附近, 地势略有隆起, 造成山中溪 流汇集于保护区中部后分为东西两支, 一支向东经 樟栋水汇入都亨罗坝河, 一支向西南流入清化河。 多种类型的水体造就了丰富的水生生物生境。

\section{2 野外调查与标本采集}

根据海拔梯度, 选取保护区中不同生境特征的 9 个水体作为采样点(图1), 海拔由低到高依次为: 
樟栋水(车八岭村, 海拔 $345 \mathrm{~m}$ )、细坝(海拔 $388 \mathrm{~m}$ )、 松树坑(海拔425 m)、大坑口(海拔450 m)、黄竹山水 库(海拔 $480 \mathrm{~m}$ )、仙人洞(海拔 $487 \mathrm{~m}$ )、企岭下(海拔 490 m)、火龙径(海拔538 m)、桐木坑(海拔751 m)。 其中松树坑、仙人洞、桐木坑位于核心区，企岭下 位于实验区与缓冲区交界，其余位于实验区。

保护区的水体以山润溪流和森林河道为主(图 2), 故采样地以此生境为主, 伴以稻田、水库、沟渠 等人工水体作为对比。其中, 樟栋水(车八岭村)采样 地有居民点, 故既有山润溪流和森林河道, 又有池 塘、沟渠、水田等人工水体; 黄竹山水库和细坝以 静水深潭的人工水体为主; 大坑口兼有稻田与山涧 溪流; 松树坑、企岭下、火龙径、仙人洞、桐木坑 均以森林河道、山润溪流为主, 涵盖砂石、砾石、 岩石底质, 伴以瀑布, 水流湍急。采样点涵盖水稻 田、溪流、天然河道、水库等水体流速不一的生境, 反映淤泥、砂石、砾石、岩石、水泥硬化等不同水 体底质类型。

分别于2019年10月和2020年5月进行大型底栖 动物调查。结合多种方法定性采集不同生境的大型 底栖动物: 针对水体底质颗粒较小(如砂石、淤泥)、
水较浅的生境(如浅滩、溪流、水稻田、沟渠)主要 运用抄网法, 直接使用中孔型(网格直径2-3 mm)手 抄网从底质或水生植物周边捞取; 针对水体底质颗 粒较大(如砾石、底岩)、水较深的生境(如河道中游), 则结合翻石法翻查底石，再用毛笔或镊子将附着的 底栖动物分离; 针对底质为硬化河床、水较深的水 体(如水库、池塘)则结合诱饵法，投放少许新鲜鸡、 鱼内脏等腥臭物于水体中静置过夜，再使用抄网捞 取吸引而来的腐食性底栖动物; 对于较深水体中体 型较大的种类(如长臂虾、淡水蟹), 则结合地笼进行 捕捉。每地点至少采集30网次, 每种采集不超出30 枚个体, 根据每网捕获数和目测来判断物种的种群 数量级别(附录1)。

对采集的底栖动物拍摄生活照, 并对部分标本 身上附着的共生底栖动物进行分离。冲洗干净后, 进行编号、登记和记录, 放入 $85 \%$ 酒精中固定。一 天后更换 $75 \%$ 酒精长期保存，存放于广州大学生命 科学学院。

\section{3 标本鉴定}

根据生活形态和标本形态, 使用连续变倍体视 显微镜对标本的关键特征(如体节、口器、尾器、生

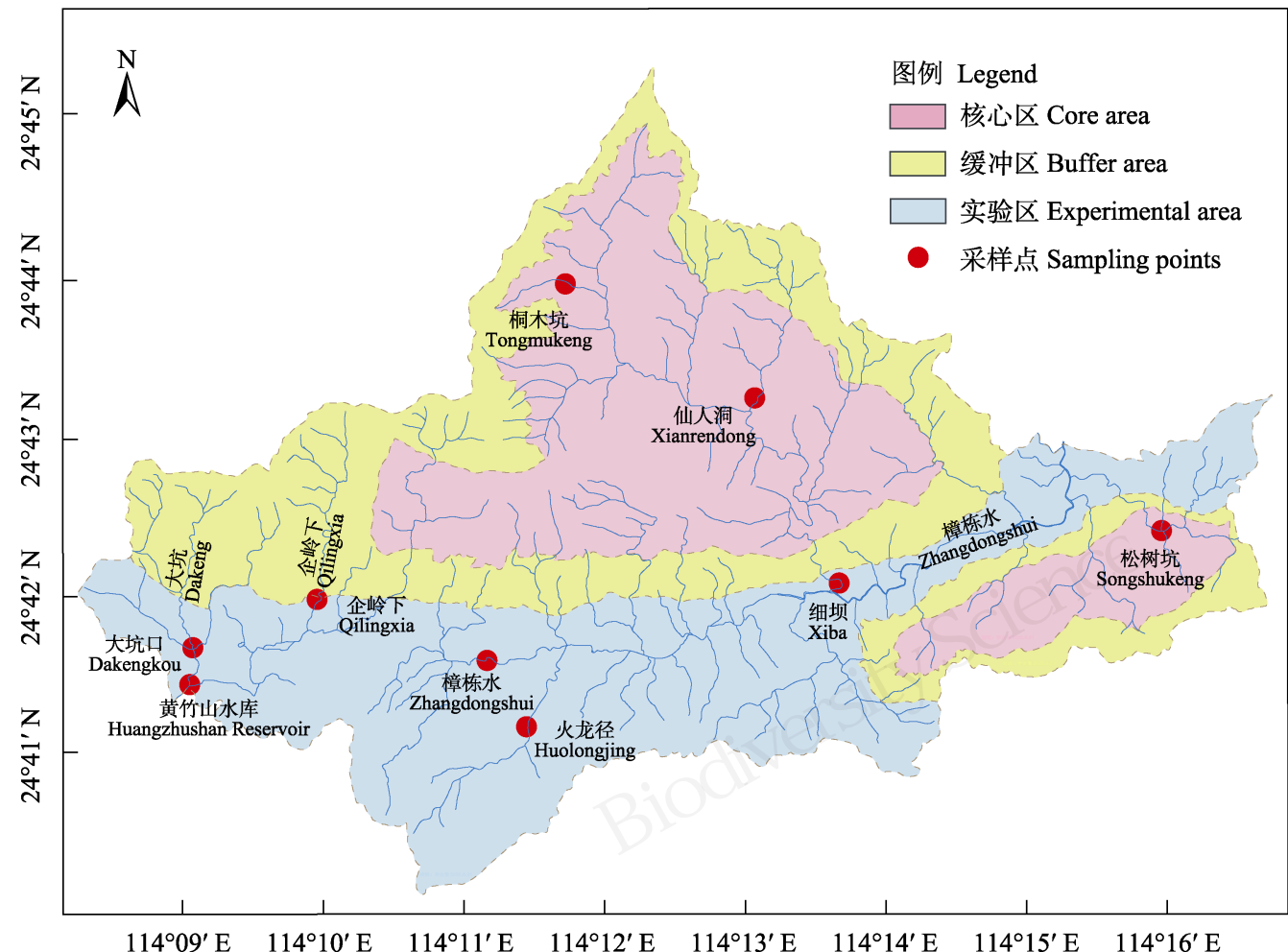

图1 车八岭国家级自然保护区水系图及采样点

Fig. 1 Sampling points and drainage map of the Chebaling National Nature Reserve 


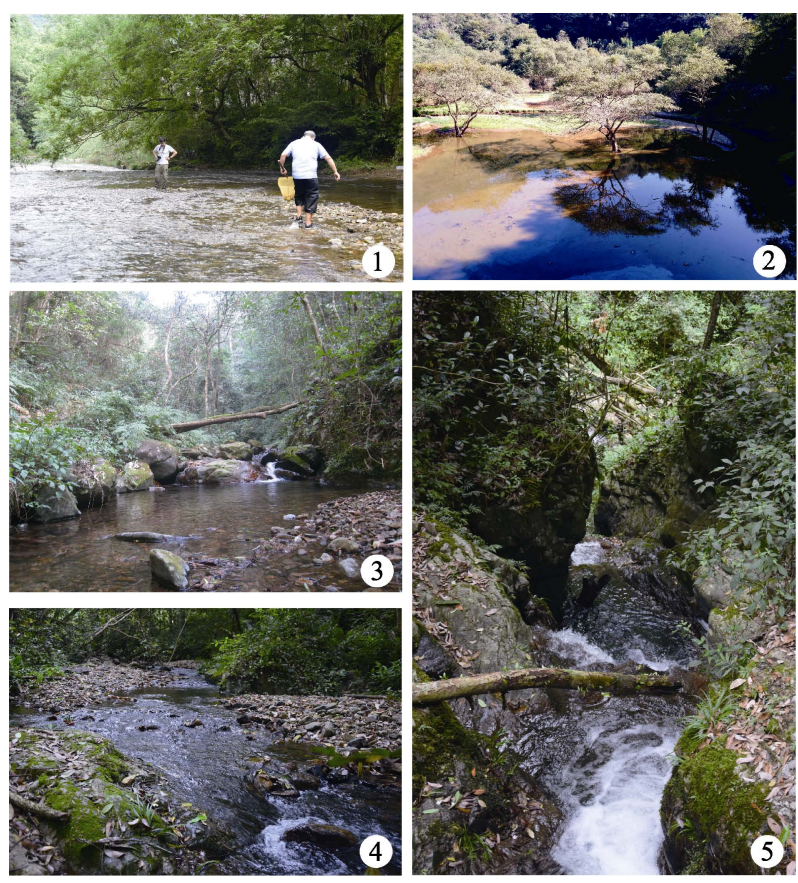

图2 采样点的典型环境。1: 樟栋水河; 2: 黄竹山水库; 3: 仙人洞; 4: 桐木坑; 5: 火龙径。

Fig. 2 Typical environments of sampling points. 1, Zhangdongshui River; 2, Huangzhushan Reservoir; 3, Xianrendong; 4, Tongmukeng; 5, Huolongjing.

殖附肢等)进行观察比对, 检索出所属类群。再通过 文献、专家问询等形式进行物种鉴定。物种名称、 分类地位、生态习性主要基于《中国动物志》、《中 国动物图谱》等经典专著(齐钟彦等, 1985; 戴爱云, 1999; 杜德俊和高力行, 2004; 梁象秋, 2004; 李新 正, 2007; 杨定和刘星月, 2010), 再根据近年出版的 专著、论文进行更新(张浩沝, 2012, 2019; 贾铭宇等, 2014; Chen et al, 2015; 李珊, 2015 ${ }^{\circledR}$; 周长发等, 2015; 姜永生, 2016; Shih et al, 2016)。

\section{2 结果}

\section{1 大型底栖动物的种类构成}

共采集标本 800 余号, 鉴定出大型底栖动物 57 种(含 19 个未定种), 隶属于 $4 门 6$ 纲 18 目 38 科, 主要 为浴虫、贝类、甲壳类及水生昆虫(附录1), 其中节 肢动物有 46 种, 约占所获物种总数的 $80 \%$ (图3)。水 生昆虫占大多数, 达 8 目 25 科 43 种, 约占所获底栖 节肢动物总数的 $90 \%$ 、占全部种类的 $73 \%$, 涵盖了水 生昆虫的主要目科。除半翅目和部分鞘翅目外, 所

(1) 李珊 (2015) 河南省襀科稚虫分类研究. 硕士学位论文, 河南科技学 院, 河南新乡.
捕获的水生昆虫基本为各类群的水生稚虫, 其中种 类最多的是蜻蜓目的稚虫, 涵盖8科: 色蟌科、溪蟌 科、蜓科、春蜓科、裂唇蜓科、大蜓科、大伪蜻科、 蜻科, 共22种, 约占节肢动物总数的 $48 \%$ 、占全部种 类的38\% (图3)。清洁水体的指示类群, 即蜉蝣目、 襀翅目、毛翅目 (Ephemeroptera、Plecoptera、 Trichoptera, EPT) 的稚虫合计 9 科13种, 约占节肢动 物的 $28 \%$ 、占全部种类的 $22 \%$ (图3)。采集到了车八 岭星齿蛉的稚虫。采集到与底栖动物共生、寄生的 物种共两种, 分别为在安远龙溪蟹 (Longpotamon anyuanense) 关节上共生的辛氏切头浴虫 (Temnocephala semperi), 以及营寄生习性的铁线虫 属一种(Gordius sp.)。

从数目及习性上来看, 调查所见、所获的大型 底栖动物大多为偏好流动清洁水体物种(附录1)。在 扁形动物中, 常见种为中国三角浴虫 (Dugesia sinensis) (图3), 附着于溪流、河道浅水区中的砾石 背后; 在贝类中, 放逸短沟蜷 (Semisulcospira libertina) (图3)的数量占绝大多数, 为各流动水体 的优势种, 静水、缓水水体中则分布有少量椭圆萝 卜螺(Radix swinhoei)及尖膀胱螺(Physa acuta), 双 壳类均较稀见; 在甲壳类中, 米虾(Caridina spp.)在 各水体较常见, 沼虾(Macrobrachium spp.) 只在部分 较深的流动水体中稀见, 淡水蟹均稀见; 在水生昆 虫中, 蜻蜓目和蜉蝣目的稚虫是流动水体中的优势 类群, 在较深的流动水体中也发现较多的广翅目稚 虫。所获底栖节肢动物大多数为肉食或杂食性, 其 余类群多为碎屑食性(附录1)。

\section{2 保护区内大型底栖动物的分布差异}

在低海拔实验区即可采集到本次记录的大部 分(47种, 约 $80 \%)$ 大型底栖动物。水生昆虫的稚虫在 大部分砂石至底岩基质的水体均可采集到。淤泥或 人工硬化底质的采样点如大坑口周边稻田、细坝、 黄竹山水库则可零星采集到椭圆萝卜螺、尖膀胱 螺、扁旋螺(Gyraulus compressus)、尖口圆扁螺 (Hippeutis cantori)等静水、缓水种类。

从海拔梯度上来看, 保护区中不同海拔的生境 间物种组成具一定差异。海拔较低的采样点 $(\leq 425 \mathrm{~m})$ 物种丰富度较高, 基本能采集到已获的水生昆虫种 类, 禎翅目、毛翅目的稚虫在低海拔尤为常见。其 中达 $60 \%(25$ 种)的水生昆虫仅在海拔最低的采样点 樟栋水(海拔345 m)采集到。非昆虫种类中, 集中分 

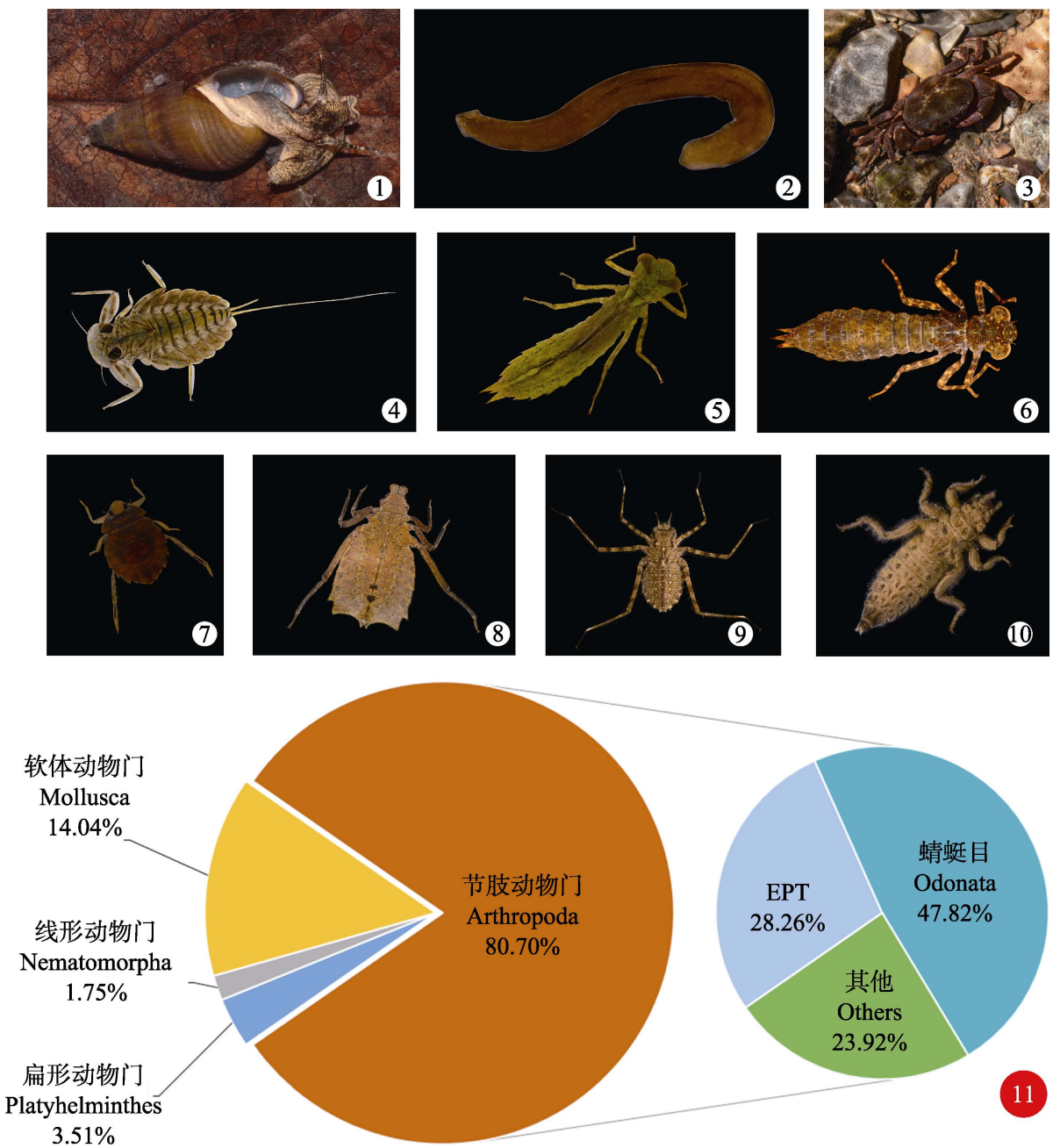

图3 调查所获大型底栖动物部分物种活体照以及各类群比例。1: 放逸短沟蜷; 2: 中国三角涡虫; 3: 安远龙溪蟹; 4: 美丽高 翔蜉; 5: 漳州佩蜓; 6: 遂昌黑额蜓; 7: 广盖蝽; 8: 折尾施春蜓; 9: 福建大伪蜻; 10: 显著闽春蜓; 11: 所获大型底栖动物的各 类群比例及其水质指示昆虫“EPT” (蜉蝣目Ephemeroptera、禎翅目Plecoptera、毛翅目Trichoptera)的比例。

Fig. 3 Photos of selected living specimens and species proportion of collected macrozoobenthos. 1, Semisulcospira libertina; 2, Dugesia sinensis; 3, Longpotamon anyuanense; 4, Epeorus melli; 5, Periaeschna zhangzhouensis; 6, Planaeschna suichangensis; 7, Aphelochelrus cantonensis; 8, Sieboldius deflexus; 9, Macromia malleifera; 10, Fukienogomphus promineus; 11, Species and EPT (Water quality indicator insects, $\mathrm{E}=$ Ephemeroptera, $\mathrm{P}=$ Plecoptera, $\mathrm{T}$ = Trichoptera) proportion of collected macrozoobenthos.

布在低海拔的有中国三角浴虫、石田螺(Sinotaia quadrata)、扁旋螺、胖掌沼虾 (Macrobrachium inflatum)等。中等海拔(425-538 m) 的采样点虽多(4 个), 但特色种类较少。特色物种河蚬 (Corbicula fluminea)仅在海拔 $487 \mathrm{~m}$ 的仙人洞水体中具一定数 量, 背角无齿蚌(Sinanodonta woodiana)则仅在海拔 $450 \mathrm{~m}$ 的大坑口偶见; 均为双壳类。即便在海拔较高 $(\geq 538 \mathrm{~m})$ 的采样点中, 也采获了适应静水的大蚊幼虫。

\section{3 讨论}

相比以软体、甲壳动物为底栖动物群落主体的 滨海红树林及河流生态系统, 森林生态系统的内陆
水体主要以溪流、湖泊、水库等形式存在, 故其底 栖动物群落以水生昆虫为主(汪兴中, 2012)。从本文 结果来看, 车八岭保护区的大型底栖动物大多属于 亚热带森林的典型物种, 其中又以蜻蜓目稚虫种类 最为丰富。从区系上看, 蜻蜓基本属于亚热带区系 种类: 溪蟌属 (Euphaea) 、闽春蜓属 (Fukienogomphus)、佩蜓属 (Periaeschna)、大伪蜻属 (Macromia)为典型的华南分布属(张浩沝, 2019)。此 外, 种群数量占优势的贝类——放逸短沟蜷是温带 及亚热带森林丘陵山溪的典型物种。其他类群中, 安远龙溪蟹、广东米虾(Caridina cantonensis)、车八 岭星齿蛉、中华越南蜉(Vietnamella sinensis)等则是 
华南或亚热带地区狭域分布种, 体现了亚热带森林 淡水生态系统的特色。

目前国内对森林内陆水体底栖动物的综合调 查较少。与本调查环境较相近的研究有神农架林地 溪流(汪兴中, 2012)、湘鄂交界的黄盖湖水系(蒋小 明等, 2011), 以及中温带的长白山林地溪流 ${ }^{(1)}$ 、吉林 省红旗河(宋聑等, 2020)等, 物种构成以蜉蝣、石蛾 稚虫等为主, 蜻蜓稚虫的记录较少。其他内陆水体 如武汉市南湖(杨明生, 2009)、赣江水系(邢圆等, 2019)、北京凉水河(常松等, 2019)、白洋淀(孙香琼 等, 2019)则以摇蚊幼虫、水生寡毛类、椎实螺类等 广适性静水种为主。其中赣江水系中寡毛类、蜉蝣 稚虫、摇蚊幼虫、蜻蜓、软体动物均有丰富的物种 记录，体现了其范围大、水文环境多样的流域特征。 国外森林生态系统的底栖动物调查较多集中在欧 洲及北美地区，如奥地利的卡林西亚(Carinthia)山 地森林溪流中以钩虾类、双翅类幼虫及EPT稚虫为 主(Weinländer \& Füreder, 2011); 捷克的波希米亚森 林(Bohemian Forest)溪流中也以双翅类幼虫和 $\mathrm{EPT}$ 稚虫为主(Svobodová et al, 2012), 蜻蜓类均很少记 述。值得注意的是, 发达地区的底栖动物调查重点 已从本底调查转向污染评估上, 许多调查案例并不 一定反映原生群落, 也会对水质指示类群有更侧重 的调查与记述。同时, 由于底栖动物门类跨度大, 虽有部分研究报道了类似生境的底栖生物种类, 但 是以某一类群为专题(如蜻蜓、贝类)、而不是以底 栖动物去综合开展(如张浩沝, 2012), 因而在整体群 落比较上存在困难。

从生态系统功能上来看, 鉴于蜻蜓目稚虫和成 虫均为捕食性, 故除反映水体小型水生动物丰富外, 结果也揭示了保护区的陆生无脊椎动物丰富, 足以 供养多种蜻蜓并维持健康的种群繁殖。此外, 丰富 的底栖节肢动物可为保护区中的鱼类等捕食者提 供食物。登陆羽化的水生稚虫实质上可将水底的能 量转移到陆上, 为诸多陆生食虫物种提供食物。

从环境指示角度上来看, 保护区调查所获的大 型底栖动物主要是洁净流动水体的中、高需氧种类, EPT昆虫占比已超过 $20 \%$ 。贝类优势种为对水体流 动性、洁净性具一定要求的放逸短沟蜷, 且数量非 常大; 偏好静水、广适性的贝类物种则仅零散出现

(1) 李玲 (2018) 冬季长白山源头溪流生境类型对调落叶分解与底栖动 物定殖的影响. 硕士学位论文, 东北师范大学, 长春.
于人工水体(如水稻田、水库、沟渠)当中。这反映 保护区中多处自然水体流动性较强, 有相当的含氧 量。低海拔实验区能采集到种类、数量均较多的蜉 蝣目、禎翅目、毛翅目等对水质要求高的昆虫类群, 显示出该保护区中有人类活动的水体受污染程度 较低。

鉴于底栖动物具水质指示及生态系统功能, 我 们建议保护区建立底栖动物长期监测体系, 以定期 比较评估保护区生态系统健康程度。监测指标应涵 盖清洁水体指示昆虫(EPT)的物种构成比、流动洁 净水体的物种构成比、物种丰富度、优势种监测等。 可考虑根据以下三方面系统设立监测样点: (1)人类 活动程度：从保护区的实验区、缓冲区、核心区分 别选取多个环境相似的水体进行定性、定量的底栖 动物群落监测, 以比较、评估人类活动的影响, 也 可据核心区监测结果建立环境标准参考值; (2)海拔 梯度：鉴于不同海拔梯度底栖动物的构成差异，可 考虑沿海拔设立3-4个梯度(如300 m、400 m、500 m、 $500 \mathrm{~m}$ 以上)的系列样点进行监测, 定期监测不同海 拔的环境质量; (3)水文属性: 可考虑在横贯保护区 的主河流樟栋水的上、中、下游河段选取定性、定 量的监测样段, 监测不同水量、流速、沉积物条件 下的底栖动物群落动态, 可对水体污染物扩散进行 快速的生态系统影响评估。在监测频次方面, 可分 别选取春夏丰水期(约4-9月)、秋冬枯水期(约10月 至次年3月)的某月中旬, 每年进行两次监测; 如条 件允许，也可选取每季某月中旬(如3、6、9、12月 中旬)进行一年四次的季节性监测。

总地来说, 车八岭保护区的大型底栖动物群落 能在一定程度上反映亚热带森林生态系统的物种 特色, 结果可为国内森林内陆水体底栖动物的综合 研究、建立保护区底栖动物长期观测体系提供基础 资料。然而, 由于各类群研究深度不一, 对底栖动 物各类群都进行鉴定存在难度, 这可能导致物种编 目中对某些类群有所侧重, 也会对洁净水体指示种 的构成比例造成偏差。同时, 比较和对照是利用底 栖动物群落进行环境评估的基本手段, 但是当前国 内底栖生物调查较为零散, 各调查地的覆盖范围、 气候水文、人类活动差异较大。加之, 尽管各类群 的研究程度不一, 部分地区的底栖动物调查已从本 底资源编目转向环境评估应用, 导致其物种既不一 定反映天然群落, 也对水质指示物种产生侧重性的 
记述; 此外, 一些调查也以某类群为专题开展。这 些因素都会降低多地间调查结果的可比性, 难以客 观评估当地本底资源情况。因而笔者建议在各典型 生态系统设立底栖动物的标准监测样地, 对底栖动 物各类群进行更全面的编目, 并建设长期且指标完 善的监测体系。只有充分摸清我国各生态系统底栖 动物的本底资源及其动态, 才能准确发挥其环境指 示与评估功能。

致谢: 感谢广东车八岭国家级自然保护区管理局对 本工作的支持。感谢贾凤龙教授、张浩永博士、黄 超博士协助物种的鉴定。感谢编辑部和审稿专家在 审阅本文时所提出的宝贵建议。

\section{ORCID}

易祖盛 (D) https://orcid.org/0000-0002-9966-7889

黄元骏 (D) https://orcid.org/0000-0001-7166-905X

\section{参考文献}

Chang S, Li XH, Wang PJ, Li ZX, Zhao LX (2019) Investigation and evaluation on zoobenthos in Liangshui River of Beijing. Beijing Water, (2), 35-39. (in Chinese with English abstract) [常松, 黎小红, 王培京, 李兆欣, 赵 立新 (2019) 北京市凉水河底栖动物现状调查与评价. 北京水务, (2), 35-39.]

Chen YH, Chen XM, Wu CC, Wang AT (2015) A new species of the genus Dugesia (Tricladida: Dugesiidae) from China. Zoological Systematics, 40, 237-249.

Committee for Terms in Ecology (2006) Chinese Terms in Ecology. Science Press, Beijing. (in Chinese) [生态学名词 审定委员会 (2006) 生态学名词. 科学出版社, 北京.]

Dai AY (1999) Fauna Sinica • Arthropoda • Crustacea • Decapoda, Crabulidae. Science Press, Beijing. (in Chinese) [戴爱 云 (1999) 中国动物志.节肢动物门.甲壳动物亚门·软甲 纲.十足目・束腹蟹科, 溪蟹科. 科学出版社, 北京.]

Du DJ, Gao LX (2004) Ecological Information of Hong Kong. Hong Kong Sanlian Press, Hong Kong. (in Chinese) [杜德 俊, 高力行 (2004) 香港生态情报. 香港三联出版社, 香 港.]

Jia MY, Liu MH, Xing B, Yu HX (2014) Larval key to genera of Tipulidae, Diptera (Insecta) from Maoershan Streams. Journal of Anhui Agricultural Sciences, 42, 7459-7462. (in Chinese with English abstract) [贾铭宇, 刘曼红, 刑博, 于 洪贤 (2014) 帽儿山溪流昆虫纲双翅目大蚊科稚虫分属 分类检索. 安徽农业科学, 42, 7459-7462.]

Jiang XM, Cheng JL, Xiong J, Zhang E, Xie ZC (2011) Macroinvertebrate community structure and bioassessment of water quality in Pohe Stream, one of the headwater streams of Huanggai Lake water-network. Resources and Environment in the Yangtze Basin, 20, 1040-1046. (in Chinese with English abstract) [蒋小明, 程建丽, 熊晶, 张 鹗, 谢志才 (2011) 黄盖湖水系河源区-皤河大型无脊椎 动物群落与水质评价. 长江流域资源与环境, 20 , 1040-1046.]

Jiang YS (2016) Atlas of Common Aquatic Organisms in Shaying River. China Water Power Press, Beijing. (in Chinese) [姜永生 (2016) 沙颖河常见水生生物图集. 中 国水利水电出版社发行部, 北京.]

Li B, Shen HL, Zhang M, Cai QH, Shao ML (2013) Changes of macrobenthos community and their relationships with environmental factors along cascading reservoirs of Xiangxi River Basin, China. Chinese Journal of Ecology, 32, 2070-2076. (in Chinese with English abstract) [李斌, 申恒 伦, 张敏, 蔡庆华, 邵美玲 (2013) 香溪河流域梯级水库 大型底栖动物群落变化及其与环境的关系. 生态学杂志, 32, 2070-2076.]

Li XZ (2007) Fauna Sinica • Arthropoda - Crustacea • Decapoda. Palaemonoidea. Science Press, Beijing. (in Chinese) [李新正 (2007) 中国动物志·无脊椎动物.甲壳 动物亚门·十足目・长臂虾总科. 科学出版社, 北京.]

Li XZ (2011) An overview of studies on marine macrobenthic biodiversity from Chinese waters: Principally from the Yellow Sea. Biodiversity Science, 19, 676-684. (in Chinese with English abstract) [李新正 (2011) 我国海洋大型底栖 生物多样性研究及展望: 以黄海为例. 生物多样性, 19, 676-684.]

Liang XQ (2004) Fauna Sinica • Arthropoda - Crustacea • Decapoda - Atyoidea. Science Press, Beijing. (in Chinese) [梁象秋 (2004) 中国动物志. 无脊椎动物. 甲壳动物亚 门·足目. 匙指虾科. 科学出版社, 北京.]

Luo YP, Jiang J, Wang LL, Shu ZF, Tong XL (2020) Vietnamella chebalingensis, a new species of the family Vietnamellidae (Ephemeroptera) from China based on morphological and molecular data. Zootaxa, 4868, 208-220.

Qi ZY, Ma XT, Liu YY (1985) The Atlas of Molluscs in China, Vol. 4. Science Press, Beijing. (in Chinese) [齐钟彦, 马绣 同，刘月英 (1985) 中国动物图谱·软体动物. 第四册. 科 学出版社, 北京.]

Shih HT, Huang C, Ng PKL (2016) A re-appraisal of the widely-distributed freshwater crab genus Sinopotamon Bott, 1967, from China, with establishment of a new genus (Crustacea: Decapoda: Potamidae). Zootaxa, 4138, 309-331.

Song D, Huo TB, Wang QS, Huang XL, Du X, Wang HB (2020) Community structure of macrozoobenthos in summer and biological evaluation of water quality in Hongqi River. Chinese Journal of Fisheries, 33(3), 42-49. (in Chinese with English abstract) [宋聘, 霍堂斌, 王秋实, 黄晓丽, 都雪, 王慧博 (2020) 红旗河夏季大型底栖动物群落结构及水 质生物学评价. 水产学杂志, 33(3), 42-49.]

Song XJ, He W, Peng YG (2017) Evaluation on ecotourism 
resources of Guangdong Chebaling National Nature Reserve. Journal of Anhui Agricultural Sciences, 45(26), 1-5. (in Chinese with English abstract) [宋相金, 何文, 彭 友贵 (2017) 广东车八岭国家级自然保护区生态旅游资 源评价. 安徽农业科学, 45(26), 1-5.]

Sun XQ, Li HC, Liao CY, Deng JZ, Sun HM, Yan MX, Wang HW (2019) Benthic invertebrate survey and water environment analysis in Baiyangdian Lake. Hebei Fisheries, (8), 40-44, 50. (in Chinese) [孙采琼, 李宏昌, 廖晨延, 邓 俊泽, 孙海明, 问明星, 王宏伟 (2019) 白洋淀底栖无脊 椎动物调查及水环境分析. 河北渔业, (8), 40-44, 50.]

Svobodová J, Matěna J, Kopácek J, Poláková S, Vrba J (2012) Spatial and temporal changes of benthic macroinvertebrate assemblages in acidified streams in the Bohemian Forest (Czech Republic). Aquatic Insects, 34, 157-172.

Wang XZ (2012) Study on the Distribution Characteristics of Stream Benthos and Its Relationship with Environmental Factors in Shennongjia Area. PhD dissertation, University of Chinese Academy of Sciences, Beijing. (in Chinese with English abstract) [汪兴中 (2012) 神农架地区溪流底栖动 物分布特征及其与环境因子关系研究. 博士学位论文, 中国科学院研究生院, 北京.]

Weinländer M, Füreder L (2011) Crayfish as trophic agents: Effect of Austropotamobius torrentium on zoobenthos structure and function in small forest streams. Knowledge \& Management of Aquatic Ecosystems, 22, 1-15.

Xiao ZS, Chen LJ, Song XJ, Shu ZF, Xiao RG, Huang XQ (2019) Species inventory and assessment of large- and medium-size mammals and pheasants using camera trapping in the Chebaling National Nature Reserve, Guangdong Province. Biodiversity Science, 27, 237-242. (in Chinese with English abstract) [肖治术, 陈立军, 宋相金, 束祖飞, 肖荣高, 黄小群 (2019) 基于红外相机技术对广东车八 岭国家级自然保护区大中型兽类与雉类的编目清查与评 估. 生物多样性, 27, 237-242.]

Xing Y, Wu XP, Ouyang S, Zhang JQ, Xu J, Yin SL, Xie ZC (2019) Assessment of macrobenthos biodiversity and potential human-induced stressors in the Ganjiang River system. Biodiversity Science, 27, 648-657. (in Chinese with English abstract) [邢圆, 吴小平, 欧阳珊, 张君倩, 徐靖, 银森录, 谢志才 (2019) 赣江水系大型底栖动物多样性 与受胁因子初探. 生物多样性, 27, 648-657.]

Xu YQ (1993) A comprehensive report on investigation in Chebaling National Nature Reserve. In: Collected Papers for Investigation in Chebaling National Nature Reserve (ed. Editorial Committee of Collected Papers for Investigation in Chebaling National Nature Reserve), pp. 1-7. Guangdong Science and Technology Press, Guangzhou. (in Chinese with English abstract) [徐燕千 (1993) 车八岭国家级自然 保护区调查研究综合报告. 见: 车八岭国家级自然保护 区调查研究论文集 (车八岭国家级自然保护区调查研究 论文集编委会编), 1-7页. 广东科技出版社, 广州.]

Yang D, Liu XY (2010) Fauna Sinica • Insecta • Megaloptera. Science Press, Beijing. (in Chinese) [杨定, 刘星月 (2010) 中国动物志·昆虫纲.广翅目. 科学出版社, 北京.]

Yang MS (2009) Studies on the Community Structure and Ecological Function of Macrozoobenthos in Lake Nanhu, Wuhan City, China. PhD dissertation, Central China Agricultural University, Wuhan. (in Chinese with English abstract) [杨明生 (2009) 武汉市南湖大型底栖动物群落 结构与生态功能的研究. 博士学位论文, 华中农业大学, 武汉.]

Zhang HM (2012) Systematic Study of Anisoptera Larvae in China (Insecta: Odonata). PhD dissertation, South China Agricultural University, Guangzhou. (in Chinese with English abstract) [张浩永 (2012) 中国差翅亚目稚虫的分 类学研究(昆虫纲: 蜻蜓目). 博士学位论文, 华南农业大 学, 广州.]

Zhang HM (2019) Dragonflies and Damselflies of China. Chongqing University Press, Chongqing. (in Chinese) [张浩 沝 (2019) 中国蜻蜓大图鉴. 重庆大学出版社, 重庆.]

Zhou CF, Su CR, Gui H (2015) Overview of Mayfly in China. Science Press, Beijing. (in Chinese) [周长发, 苏翠荣, 归 鸿 (2015) 中国蜉蝣概述. 科学出版社, 北京.]

(责任编委: 吴纪华 责任编辑: 间文杰)

\section{附录 Supplementary Material}

附录1 车八岭国家级自然保护区大型底栖动物名录、种群大小、分布与习性

Appendix 1 Catalogue, population size, habit and distribution of macrozoobenthos in the Chebaling National Nature Reserve https://www.biodiversity-science.net/fileup/PDF/2020304-1.pdf 
附录1 车八岭国家级自然保护区大型底栖动物名录、种群大小、分布与习性。+表示稀见种(1-5个体), ++表示常见种(5-20个体), +++表示优势种(20以上个体)。Pl: 浮游生物食者; Ph: 植食 者; C: 肉食者; O: 杂食者; D: 碎屑食者; U: 未见资料; H: 高; M: 中; L: 低。

Appendix 1 Catalogue, population size, habit and distribution of macrozoobenthos in the Chebaling National Nature Reserve. +, ++, +++ represent rare (1-5 individuals), common (5-20 individuals) and dominant species (20+ individuals) respectively. Pl, Planktophagous; Ph, Phytophagous; C, Carnivorous; O, Omnivorous; D, Detritivorous; U, Unknown; H, High; M, Medium; L, Low.

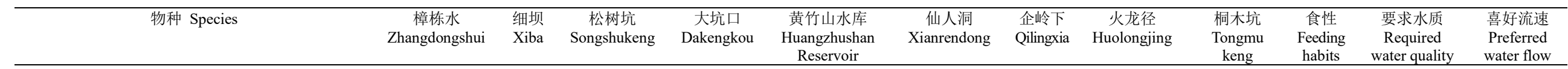

\section{扁形动物门 Platyhelminthes}

\section{涡虫纲 Turbellaria}

切头科 Temnocephalidae

辛氏切头涡虫 Temnocephala semperi

三角涡虫科 Dugesiidae

中国三角涡虫 Dugesia sinensis

\section{线形动物门 Nematomorpha}

\section{铁线虫科 Gordiidae}

铁线虫属一种 Gordlius sp

\section{软体动物门 Mollusca}

\section{腹足纲 Gastropoda}

\section{中腹足目 Mesogastropoda}

短沟蜷科 Semisulcospiridae

\section{新腹足目 Caenogastropoda}




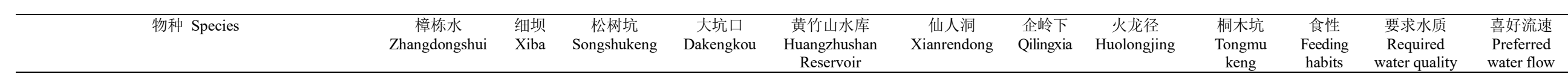

\section{田螺科 Viviparidae}

石田螺 Sinotaia quadrata

\section{基眼目 Basommatophora}

\section{扁蜷螺科 Planorbidae}

扁旋螺 Gyraulus compressus

尖口圆扁螺 Hippeutis cantori

\section{椎实螺科 Lymnaeidae}

椭圆夢卜螺 Radix swinhoei

\section{膀腃螺科 Physidae}

尖膀胱螺 Physa acuta

双壳纲 Bivalvia

蚌目 Unionoida

蚌科 Unionidae

背角无齿蚌 Sinanodonta woodiana

Pl M

蚬目 Corbiculoidea

\section{蚬科 Corbiculida}




\begin{tabular}{|c|c|c|c|c|c|c|c|c|c|c|c|c|}
\hline 物种 Species & $\begin{array}{c}\text { 樟栋水 } \\
\text { Zhangdongshui }\end{array}$ & $\begin{array}{l}\text { 细坝 } \\
\text { Xiba }\end{array}$ & $\begin{array}{c}\text { 松树坑 } \\
\text { Songshukeng }\end{array}$ & $\begin{array}{c}\text { 大坑口 } \\
\text { Dakengkou }\end{array}$ & $\begin{array}{c}\text { 黄竹山水库 } \\
\text { Huangzhushan } \\
\text { Reservoir }\end{array}$ & $\begin{array}{c}\text { 仙人洞 } \\
\text { Xianrendong }\end{array}$ & $\begin{array}{l}\text { 企岭下 } \\
\text { Qilingxia }\end{array}$ & $\begin{array}{c}\text { 火龙径 } \\
\text { Huolongjing }\end{array}$ & $\begin{array}{c}\text { 桐木坑 } \\
\text { Tongmu } \\
\text { keng } \\
\end{array}$ & $\begin{array}{c}\text { 食性 } \\
\text { Feeding } \\
\text { habits }\end{array}$ & $\begin{array}{c}\text { 要求水质 } \\
\text { Required } \\
\text { water quality }\end{array}$ & $\begin{array}{c}\text { 喜好流速 } \\
\text { Preferred } \\
\text { water flow }\end{array}$ \\
\hline \multicolumn{13}{|l|}{ 节肢动物门 Arthropoda } \\
\hline \multicolumn{13}{|l|}{ 软甲纲 Malacostraca } \\
\hline \multicolumn{13}{|l|}{ 十足目 Decapoda } \\
\hline \multicolumn{13}{|l|}{ 匙指虾科 Atyoidae } \\
\hline 广东米虾 Caridina cantonensis & +++ & +++ & +++ & + & +++ & +++ & + & ++ & + & $\mathrm{C}$ & M & M \\
\hline \multicolumn{13}{|l|}{ 长臂虾科 Palaemonidae } \\
\hline 胖掌沼虾 Macrobrachium inflatum & + & + & + & & & & & & & $\mathrm{C}$ & M & M \\
\hline \multicolumn{13}{|l|}{ 溪蟹科 Potamidae } \\
\hline 安远龙溪蟹 Longpotamon anyuanense & + & & + & & & + & + & & + & $\mathrm{C}$ & M & M \\
\hline \multicolumn{13}{|l|}{ 昆虫纲 Insecta } \\
\hline \multicolumn{13}{|l|}{ 蜉蝣目 Ephemeroptera } \\
\hline \multicolumn{13}{|l|}{ 短丝蜉科 Siphlonuridae } \\
\hline 短丝蜉属一种 Siphlonurus sp. & + & & & & & + & & & + & $\mathrm{O}$ & $\mathrm{H}$ & $\mathrm{L}$ \\
\hline \multicolumn{13}{|l|}{ 等蜉科 Isonychiidae } \\
\hline 等蜉属一种 Isonychia sp. & + & & & & & & & & + & $\mathrm{O}$ & $\mathrm{H}$ & M \\
\hline \multicolumn{13}{|l|}{ 扁蜉科 Heptageniidae } \\
\hline 扁蜉属一种 Heptagenia sp. & + & & & & & + & & & & $\mathrm{O}$ & $\mathrm{H}$ & M \\
\hline
\end{tabular}


易祖盛, 黄元骏, 易晖, 张新旺, 李文俊 (2021) 广东车八岭国家级自然保护区大型底栖动物多样性. 生物多样性, 29, 680-687. http://www.biodiversity-science.net/CN/10.17520/biods.2020304

\begin{tabular}{|c|c|c|c|c|c|c|c|c|c|c|c|c|}
\hline 物种 Species & $\begin{array}{c}\text { 樟栋水 } \\
\text { Zhangdongshui }\end{array}$ & $\begin{array}{l}\text { 细坝 } \\
\text { Xiba }\end{array}$ & $\begin{array}{c}\text { 松树坑 } \\
\text { Songshukeng }\end{array}$ & $\begin{array}{c}\text { 大坑口 } \\
\text { Dakengkou }\end{array}$ & $\begin{array}{c}\text { 黄竹山水库 } \\
\text { Huangzhushan } \\
\text { Reservoir }\end{array}$ & $\begin{array}{c}\text { 仙人洞 } \\
\text { Xianrendong }\end{array}$ & $\begin{array}{l}\text { 企岭下 } \\
\text { Qilingxia }\end{array}$ & $\begin{array}{c}\text { 火龙径 } \\
\text { Huolongjing }\end{array}$ & $\begin{array}{l}\text { 桐木坑 } \\
\text { Tongmu } \\
\text { keng } \\
\end{array}$ & $\begin{array}{c}\text { 食性 } \\
\text { Feeding } \\
\text { habits }\end{array}$ & $\begin{array}{c}\text { 要求水质 } \\
\text { Required } \\
\text { water quality }\end{array}$ & $\begin{array}{c}\text { 喜好流速 } \\
\text { Preferred } \\
\text { water flow }\end{array}$ \\
\hline 美丽高翔蜉 Epeorus melli & + & & & & & & & & & $\mathrm{O}$ & $\mathrm{H}$ & M \\
\hline \multicolumn{13}{|l|}{ 四节蜉科 Baetidae } \\
\hline 四节蜉属一种 Baetis sp. & + & & & & & & & & & $\mathrm{O}$ & $\mathrm{H}$ & M \\
\hline 具翅原二翅蜉 Procloeon pennulatum & ++ & & & & & & & & & $\mathrm{O}$ & $\mathrm{H}$ & M \\
\hline \multicolumn{13}{|l|}{ 越南蜉科 Vietnamellidae } \\
\hline 中华越南蜉 Vietnamella sinensis & + & & & & & & & & & $\mathrm{O}$ & $\mathrm{H}$ & M \\
\hline \multicolumn{13}{|l|}{ 蜉蝣科 Ephemeridae } \\
\hline 斑点蜉 Ephemera spilosa & + & & & & & & & & ++ & $\mathrm{O}$ & $\mathrm{H}$ & M \\
\hline \multicolumn{13}{|l|}{ 蜻蜓目 Odonata } \\
\hline \multicolumn{13}{|l|}{ 色蟌科 Calopterygidae } \\
\hline 华艳色蟌 Neurobasis chinensis & & + & & & & & & & & $\mathrm{C}$ & $\mathrm{H}$ & M \\
\hline 色蟌科末定种 1 Calopterygidae undefined sp. 1 & & + & & & & & & & & $\mathrm{C}$ & $\mathrm{H}$ & M \\
\hline 色蟌科末定种 2 Calopterygidae undefined sp. 2 & & & & & & & & & & $\mathrm{C}$ & $\mathrm{H}$ & M \\
\hline 色蟌科末定种 3 Calopterygidae undefined sp. 3 & & & & & & & & & & $\mathrm{C}$ & $\mathrm{H}$ & M \\
\hline \multicolumn{13}{|l|}{ 溪蟌科 Euphaeidae } \\
\hline 方带溪蟌 Euphaea decorata & + & + & & & & & & & & $\mathrm{C}$ & $\mathrm{H}$ & M \\
\hline 褐翅溪蟌 Euphaea opaca & & + & & & & & & & & $\mathrm{C}$ & $\mathrm{H}$ & M \\
\hline
\end{tabular}




\begin{tabular}{|c|c|c|c|c|c|c|c|c|c|c|c|c|}
\hline 物种 Species & $\begin{array}{c}\text { 樟栋水 } \\
\text { Zhangdongshui }\end{array}$ & $\begin{array}{l}\text { 细坝 } \\
\text { Xiba }\end{array}$ & $\begin{array}{c}\text { 松树坑 } \\
\text { Songshukeng }\end{array}$ & $\begin{array}{c}\text { 大坑口 } \\
\text { Dakengkou }\end{array}$ & $\begin{array}{c}\text { 黄竹山水库 } \\
\text { Huangzhushan } \\
\text { Reservoir }\end{array}$ & $\begin{array}{c}\text { 仙人洞 } \\
\text { Xianrendong }\end{array}$ & $\begin{array}{l}\text { 企岭下 } \\
\text { Qilingxia }\end{array}$ & $\begin{array}{c}\text { 火龙径 } \\
\text { Huolongjing }\end{array}$ & $\begin{array}{c}\text { 桐木坑 } \\
\text { Tongmu } \\
\text { keng } \\
\end{array}$ & $\begin{array}{c}\text { 食性 } \\
\text { Feeding } \\
\text { habits }\end{array}$ & $\begin{array}{c}\text { 要求水质 } \\
\text { Required } \\
\text { water quality }\end{array}$ & $\begin{array}{c}\text { 喜好流速 } \\
\text { Preferred } \\
\text { water flow }\end{array}$ \\
\hline \multicolumn{13}{|l|}{ 蜓科 Aeshnidae } \\
\hline 漳州佩蜓 Periaeschna zhangzhouensis & + & & & & & & & & + & $\mathrm{C}$ & $\mathrm{H}$ & M \\
\hline 福临佩蜓 Periaeschna flinti & + & & & & & & & & & $\mathrm{C}$ & $\mathrm{H}$ & M \\
\hline 幽灵黑额蜓 Planaeschna skiaperipola & + & & & & & & & & + & $\mathrm{C}$ & $\mathrm{H}$ & M \\
\hline 遂昌黑额蜓 Planaeschna suichangensis & + & + & & & & & & & + & $\mathrm{C}$ & $\mathrm{H}$ & M \\
\hline \multicolumn{13}{|l|}{ 春蜓科 Calopterygidae } \\
\hline 海南亚春蜓 Asiagomphus hainanensis & & & & & & & & & & $\mathrm{C}$ & $\mathrm{H}$ & M \\
\hline 深山闽春蜓 Fukienogomphus prometheus & + & & & & & & & & & $\mathrm{C}$ & $\mathrm{H}$ & M \\
\hline 显著闽春蜓 Fukienogomphus promineus & + & & & & & & & & & $\mathrm{C}$ & $\mathrm{H}$ & M \\
\hline 扭尾㬢春蜓 Heliogomphus retroflexus & + & + & & & & & & & & $\mathrm{C}$ & $\mathrm{H}$ & M \\
\hline 中华长钩春蜓 Ophiogomphus sinicus & + & & & & & & & & & $\mathrm{C}$ & $\mathrm{H}$ & M \\
\hline 折尾施春蜓 Sieboldius deflexus & + & & & & & & & & & $\mathrm{C}$ & $\mathrm{H}$ & M \\
\hline \multicolumn{13}{|l|}{ 裂唇蜓科 Chlorogomphidae } \\
\hline 蝴蝶裂唇蜓 Chlorogomphus papilio & + & & & & & & & & & $\mathrm{C}$ & $\mathrm{H}$ & M \\
\hline \multicolumn{13}{|l|}{ 大蜓科 Cordulegastridae } \\
\hline 巨圆慰大蜓 Anotogaster sieboldii & & & & & & & & & & $\mathrm{C}$ & $\mathrm{H}$ & M \\
\hline 大伪蜻科 Macromiidae & & & & & & & & & & & & \\
\hline
\end{tabular}


易祖盛, 黄元骏, 易晖, 张新旺, 李文俊 (2021) 广东车八岭国家级自然保护区大型底栖动物多样性. 生物多样性, 29, 680-687. http://www.biodiversity-science.net/CN/10.17520/biods.2020304

\begin{tabular}{|c|c|c|c|c|c|c|c|c|c|c|c|c|}
\hline 物种 Species & $\begin{array}{c}\text { 樟栋水 } \\
\text { Zhangdongshui }\end{array}$ & $\begin{array}{l}\text { 细坝 } \\
\text { Xiba }\end{array}$ & $\begin{array}{c}\text { 松树坑 } \\
\text { Songshukeng }\end{array}$ & $\begin{array}{c}\text { 大坑口 } \\
\text { Dakengkou }\end{array}$ & $\begin{array}{c}\text { 黄竹山水库 } \\
\text { Huangzhushan } \\
\text { Reservoir }\end{array}$ & $\begin{array}{c}\text { 仙人洞 } \\
\text { Xianrendong }\end{array}$ & $\begin{array}{l}\text { 企岭下 } \\
\text { Qilingxia }\end{array}$ & $\begin{array}{c}\text { 火龙径 } \\
\text { Huolongjing }\end{array}$ & $\begin{array}{c}\text { 桐木坑 } \\
\text { Tongmu } \\
\text { keng } \\
\end{array}$ & $\begin{array}{c}\text { 食性 } \\
\text { Feeding } \\
\text { habits }\end{array}$ & $\begin{array}{c}\text { 要求水质 } \\
\text { Required } \\
\text { water quality }\end{array}$ & $\begin{array}{c}\text { 喜好流速 } \\
\text { Preferred } \\
\text { water flow }\end{array}$ \\
\hline 福建大伪蜻 Macromia malleifera & + & & & & & & & & + & $\mathrm{C}$ & $\mathrm{H}$ & M \\
\hline 伯兰大伪蜻 Macromia berlandi & + & & & & & & & & + & $\mathrm{C}$ & $\mathrm{H}$ & M \\
\hline \multicolumn{13}{|l|}{ 蜻科 Libellulidae } \\
\hline 黄蜻 Pantala flavescens & + & & & & & & & & & $\mathrm{C}$ & M & M \\
\hline 彩虹蜻 Zygonyx iris & + & & & & & & & & & $\mathrm{C}$ & $\mathrm{H}$ & M \\
\hline \multicolumn{13}{|l|}{ 襀翅目 Plecoptera } \\
\hline \multicolumn{13}{|l|}{ 襀科 Perlidae } \\
\hline 新禎属一种 Neoperla sp. & + & & & & & & & & + & $\mathrm{O}$ & $\mathrm{H}$ & $\mathrm{H}$ \\
\hline 禎科未定种1 Perlidae undefined sp. 1 & +++ & & & & & & & & & $\mathrm{O}$ & $\mathrm{H}$ & $\mathrm{H}$ \\
\hline 禎科未定种2 Perlidae undefined sp. 2 & +++ & & & & & & & & & $\mathrm{O}$ & $\mathrm{H}$ & $\mathrm{H}$ \\
\hline \multicolumn{13}{|l|}{ 毛翅目 Trichoptera } \\
\hline \multicolumn{13}{|l|}{ 纹石蛾科 Hydropsychidae } \\
\hline 纹石蛾未定种 Hydropsychidae undefined sp. & +++ & & & & & & & & & $\mathrm{D}$ & $\mathrm{H}$ & $\mathrm{H}$ \\
\hline \multicolumn{13}{|l|}{ 角石蛾科 Stenpsychidae } \\
\hline 角石蛾属一种 Stenpsyche sp. & +++ & +++ & & & & + & & & ++ & $\mathrm{D}$ & $\mathrm{H}$ & $\mathrm{H}$ \\
\hline \multicolumn{13}{|l|}{ 半翅目 Hemiptera } \\
\hline 盖蝽科 Aphelochemdae & & & & & & & & & & & & \\
\hline
\end{tabular}


易祖盛, 黄元骏, 易晖, 张新旺, 李文俊 (2021) 广东车八岭国家级自然保护区大型底栖动物多样性. 生物多样性, 29, 680-687. http://www.biodiversity-science.net/CN/10.17520/biods.2020304

\begin{tabular}{|c|c|c|c|c|c|c|c|c|c|c|c|c|}
\hline 物种 Species & $\begin{array}{c}\text { 樟栋水 } \\
\text { Zhangdongshui }\end{array}$ & $\begin{array}{l}\text { 细坝 } \\
\text { Xiba }\end{array}$ & $\begin{array}{c}\text { 松树坑 } \\
\text { Songshukeng }\end{array}$ & $\begin{array}{c}\text { 大坑口 } \\
\text { Dakengkou }\end{array}$ & $\begin{array}{c}\text { 黄竹山水库 } \\
\text { Huangzhushan } \\
\text { Reservoir }\end{array}$ & $\begin{array}{c}\text { 仙人洞 } \\
\text { Xianrendong }\end{array}$ & $\begin{array}{l}\text { 企岭下 } \\
\text { Qilingxia }\end{array}$ & $\begin{array}{c}\text { 火龙径 } \\
\text { Huolongjing }\end{array}$ & $\begin{array}{c}\text { 桐木坑 } \\
\text { Tongmu } \\
\text { keng } \\
\end{array}$ & $\begin{array}{c}\text { 食性 } \\
\text { Feeding } \\
\text { habits }\end{array}$ & $\begin{array}{c}\text { 要求水质 } \\
\text { Required } \\
\text { water quality }\end{array}$ & $\begin{array}{c}\text { 喜好流速 } \\
\text { Preferred } \\
\text { water flow }\end{array}$ \\
\hline 广盖蝽 Aphelochelrus cantonensis & + & & & & & & & & & $\mathrm{C}$ & $\mathrm{U}$ & $\mathrm{L}$ \\
\hline \multicolumn{13}{|l|}{ 广翅目 Megaloptera } \\
\hline \multicolumn{13}{|l|}{ 齿蛉科 Corydalidae } \\
\hline 车八岭星齿蛉 Protohermes chebalingensis & +++ & & & & & + & & & ++ & $\mathrm{C}$ & $\mathrm{H}$ & $\mathrm{H}$ \\
\hline \multicolumn{13}{|l|}{ 鱼蛉科 Corydalidae } \\
\hline 斑鱼蛉属一种 Neochauliodes sp. & ++ & & & & & ++ & & & ++ & $\mathrm{C}$ & $\mathrm{H}$ & $\mathrm{H}$ \\
\hline \multicolumn{13}{|l|}{ 鞘翅目 Coleoptera } \\
\hline \multicolumn{13}{|l|}{ 扁泥甲科 Psephenidae } \\
\hline 扁泥甲属一种 Mataeopsephus sp. & ++ & + & & & & & & & +++ & $\mathrm{D}$ & $\mathrm{U}$ & $\mathrm{U}$ \\
\hline \multicolumn{13}{|l|}{ 龙虫科 Dytiscidae } \\
\hline 刻翅龙虫属一种 Copelatus sp. & + & & & & & & & & & $\mathrm{C}$ & M & $\mathrm{L}$ \\
\hline \multicolumn{13}{|l|}{ 牙甲科 Hydrophilidae } \\
\hline 长节牙甲属一种 Laccobius sp. & + & & & & & & & & & $\mathrm{C}$ & M & $\mathrm{L}$ \\
\hline \multicolumn{13}{|l|}{ 双翅目 Diptera } \\
\hline \multicolumn{13}{|l|}{ 大蚊科 Tipulidae } \\
\hline 大蚊未定种 Tipulidae undefined species & & & & & & & & & ++ & $\mathrm{D}$ & $\mathrm{L}$ & $\mathrm{L}$ \\
\hline \multicolumn{13}{|l|}{ 摇蚊科 Chironomidae } \\
\hline 摇蚊未定种 Chironomidae undefined species & & & & & +++ & & & & & $\mathrm{D}$ & $\mathrm{L}$ & $\mathrm{L}$ \\
\hline
\end{tabular}

